\title{
A Learning-by-Doing Technology Program Based on Traditional Engineer- ing Foundations and Hands-on Implementation-Driven
}

\author{
Dr. Jorge Crichigno, Northern New Mexico College
}

Jorge Crichigno received the BSc degree in Electrical Engineering from the Catholic University of Asuncion, Paraguay, in 2004, the MSc and PhD degrees in Computer Engineering from the University of New Mexico, Albuquerque, NM, in 2008 and 2009 respectively. In 2007, he was visiting the Wireless Sensor Network Lab in the School of Electronic, Information and Electrical Engineering at Shanghai Jiao Tong University. His research interests include wireless and optical networks, graph theory, mathematical optimization, network security and undergraduate STEM education. He has served as reviewer and TPC member of IEEE journals and conferences and as panelist for NSF STEM undergraduate education initiatives.

\section{Dr. Ivan Lopez Hurtado, Northern New Mexico College}

IVAN LOPEZ HURTADO received his B.S. degree in Industrial Physics Engineering from Tec de Monterrey, Monterrey, Mexico, 1995. M.S. degree in Automation from Tec de Monterrey, Monterrey, Mexico, 1998 and Ph.D. in Electrical Engineering from the University of New Mexico, Albuquerque, NM, USA in 2008. He is currently the Department of Engineering, Chair at Northern New Mexico College.

\section{Dr. Alfredo J. Perez, Northern New Mexico College}

Alfredo J. Perez received his M.S. degree in Computer Science and Ph.D. degree in Computer Science and Engineering from the University of South Florida, in 2009 and 2011 respectively. Since 2011, he has been with Northern New Mexico College, Espanola (NM), where he is currently an Assistant Professor in the Department of Engineering. Prior to coming to USA to pursue graduate studies, he obtained a B.S degree in Systems Engineering from Universidad del Norte in Barranquilla Colombia (2006). His research interests are in the areas of Mobile Computing/Sensing, Data mining, Distributed Systems and STEM education. He has coauthored several journal and conference papers as well as the book "Location Aware Information systems - Developing Real-time Tracking Systems", published by CRC Press.

\section{Mr. Raul R Peralta, Northern New Mexico College}

Raul Peralta-Meza received the B.Sc. degree in Electronic Engineering from San Agustin National University in Arequipa, Peru, in 1993. He obtained a M.Sc. degree in Computer Science at the Pontifical Catholic University of Peru in 2000. He earned a M.Sc. degree in Computer Engineering from The University of New Mexico in 2007 as well. Since March 2012, he has been a full-time faculty member in the Department of Engineering at Northern New Mexico College, Espanola, New Mexico. 


\title{
A Learning-by-Doing Technology Program Based on Traditional Engineering Foundations and Hands-on Implementation-Driven
}

\begin{abstract}
This paper presents the implementation of an Information Engineering Technology (IET) program that borrows from traditional engineering programs to build student foundations and at the same time prepares industry-ready professionals. The paper describes the building blocks of the program, focusing on curriculum and student outcomes. The IET curriculum is based on a learning-by-doing approach and includes intensive hands-on activities. By partnering with the industry, students are exposed since their freshman year to real industrial tools, hands-on activities and simple engineering design, which helps in engaging and motivating them to persist in the program. Student outcomes are analyzed according to specific knowledge, technique and skills relevant to the local stakeholders. Assessment and evaluation of student outcomes, collected through direct and indirect measures, demonstrate the effectiveness of the IET program to prepare students for the market-place and for attaining student outcomes.
\end{abstract}

\section{Index Terms}

Student outcomes, Information Engineering Technology, hands-on activities, ABET, computer networks.

\section{Introduction}

According to ABET, engineering technology programs are more practical than theoretical in nature. Engineering technology programs, in contrast to engineering programs, focus on application and implementation while the latter often focus on theory and conceptual design ${ }^{1}$. The two different types of programs have been compared by the industry and academia in recent years. Engineering graduates hired by the industry are not ready to start working from day one without additional training - and often many months of it. According to Groose ${ }^{2}$, that's because most graduates come from research-based schools that emphasize the engineering sciences and theory over the teaching of practical applications of that knowledge. On the other, engineering technology graduates may lack of fundamental knowledge that may be needed to produce innovative solutions. Colleges and universities are taking note of this issue and are introducing new elements in engineering and engineering technology curricula ${ }^{2,3,4}$.

The gap problem between pure technology programs (extremely focused on technology) and engineering programs (only focused on concepts and theory) can be addressed in different ways. One of them is to endow engineering technology programs with sound foundations of science and math present in engineering programs. A resulting engineering technology program would then be hands-on implementation-driven constructed on math and science foundation. 
This paper presents the implementation of an Information Engineering Technology (IET) program at Northern New Mexico College (NNMC) that borrows from traditional engineering programs to build student foundations and at the same time prepares industry-ready professionals. The paper describes the building blocks of the program, focusing on curriculum and student outcomes. The IET curriculum is based on a learning-by-doing approach and includes intensive hands-on activities. By partnering with the industry, students are exposed since their freshman year to real industrial tools, hands-on activities and simple engineering design, which helps in engaging and motivating them to persist in the program. Student outcomes are analyzed according to specific knowledge, technique and skills relevant to the local stakeholders. Assessment and evaluation of student outcomes, collected through direct and indirect measures, demonstrate the effectiveness of the IET program to prepare students for the market-place and for attaining student outcomes.

The rest of this paper is organized as follows. Section 2 presents background information of NNMC. Section 3 describes the IET program and its main features. Section 4 discusses the student outcomes of the IET and the methodology for assessment and evaluation. Section 5 describes the impact of the IET model on students from their perspective, and Section 6 concludes the paper.

\section{Background information}

Northern New Mexico College is located in a rural area. The student body demographics is $73 \%$ Hispanic, $11 \%$ Native American students and 16\% other. The institution at large serves a community with a population of 10,495 inhabitants with a medium household income (20052009 ) of $\$ 34,186$. According to the 2010 US Census Bureau, $27.2 \%$ of the population and $16.5 \%$ of families were below the poverty line. In the Spring 2009, the overall graduation rate reported for the institution was only $7 \%$. The current 6-year graduation rate for the main three urban universities in the state of $\mathrm{NNMC}$ is $44 \%$, and the three comprehensive regional universities graduate $25 \%$. The most recent placement indicators at the College show that $93 \%$ of the incoming student population is placed in remedial math, and the main student feeder highschool's ranking is 3/10 according to Great Schools, Inc.

The Department of Engineering houses the IET program, where there are 60 students enrolled in the program. There are three full-time faculty members exclusively dedicated to this program, plus the chair of the department who contributes to the IET and the Mechanical Engineering program. The IET faculty are professionals who studied Engineering Physics, Electrical Engineering, Electronic and Computer Engineering, Computer Science, Physics and Business Administration, and specialized in technological areas such as networks, data communications, computer hardware, programming, databases, project management, and telecommunications. The faculty members (full-time and part-time) have experience in both industry and academia. Even through full-time faculty members come from academic environments, they are in constant 
training in hands-on courses and certificate such as computer networks (Cisco), mobile computing (Android) and Java, programmable logic devices (Xilinx), and databases (OracleMySQL). As a spin-off of the program of studies, students can acquire industrial certifications before they finish the program. The program follows the guidelines from the ACM/IEEE computer society for IT undergraduate programs ${ }^{5}$ and does not limit student's knowledge to certifications but to complement the theory with hands-on activities that strengthens their knowledge.

The Department of Engineering started the ABET accreditation processes in the year 2009, which culminated with an initial visit by an ETAC team on September of 2013. Official results are expected by Fall 2014. In order to comply with program objectives (Criterion 2), student outcomes (Criterion 3), curriculum (Criterion 5) and facilities (Criterion 7), the department through an industrial advisory board built a roadmap in 2009 that included curriculum development based on intensive hands-on activities supported by state-of-the art facilities. Periodical annual reviews via assessment and evaluation meetings (Criterion 4) helped to finetune the program to the current state. Figure 1 illustrates the process followed to define, evaluate and assess student outcomes and program objectives. More details about the process of Figure 1 are discussed in the next sections.

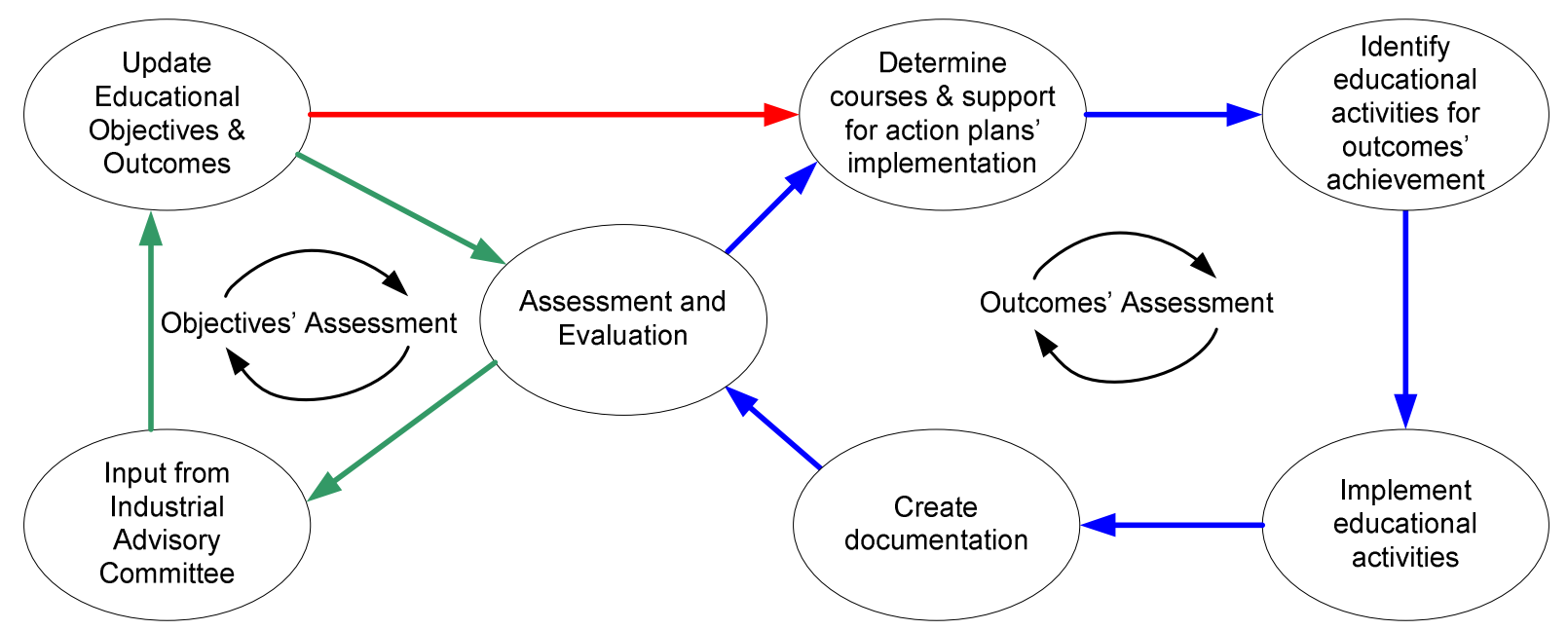

Figure 1. Process for defining, evaluating, and assessing student outcomes and program objectives.

\section{IET program}

\subsection{Overview}

Different curriculum models exist for engineering and engineering technology programs. In Information Technology (IT), some programs are implemented using pillars first ${ }^{5}$. The pillars of IT are computer networks, programming, web system, databases, and human-computer 
interaction $(\mathrm{HCI})^{5}$. This approach introduces the details of the IT pillars first (early during program of studies) and provides the integration later in the curriculum. Introductory courses, such as Introduction to Computer Networks, Computer Programming Fundamentals, and Introduction to Engineering, have no pre-requisites and are taken during the freshman year. These courses give students a detailed, complete view of each of these knowledge areas on their own. Additionally, the courses extensively expose freshman students to hands-on activities and simple engineering design, which helps engaging and motivating them to persist in the program ${ }^{4}$.

At NNMC, the IET program follows a learning-by-doing approach that borrows ideas from pillars first approach. The IET program exposes freshman students to the following three pillars of IT: computer networks, programming, and databases. They are also exposed to a project-based Introduction to Engineering course that presents, in a hands-on manner, the areas of the Information Engineering Technology discipline. The following two pillars of IT, HCI and web systems, are covered in subsequent semesters once students already have strong foundations of object-oriented programming. Usually, HCI is taken between the third and fifth semesters, and web systems during the senior year. The benefits of such or similar models ${ }^{3}$ include the improvement in retention and graduation rates. The model shifts traditional emphasis on prerequisite requirements to an emphasis on engineering motivation for those pre-requisites; just-intime structure ${ }^{3}$. Table 1 compares a traditional and the proposed models.

Table 1. Comparison between a traditional model and the model implemented at NNMC.

\begin{tabular}{|l|l|}
\hline \multicolumn{1}{|c|}{ Traditional Models } & \multicolumn{1}{|c|}{ Model Implemented at NNMC } \\
\hline Emphasis on pre-requisite requirements & $\begin{array}{l}\text { Emphasis on engineering motivation for } \\
\text { those pre-requisites; just-in-time structure }\end{array}$ \\
\hline $\begin{array}{l}\text { Introduce students to some pillars areas (e.g., } \\
\text { computer networks) at their senior year }\end{array}$ & $\begin{array}{l}\text { Introduce students to pillars areas early } \\
\text { (freshman or sophomore years) during the } \\
\text { course work }\end{array}$ \\
\hline Concepts taught only theoretical & $\begin{array}{l}\text { Concepts reinforced and introduced with } \\
\text { extensive hands-on activities }\end{array}$ \\
\hline $\begin{array}{l}\text { Abstract engineering design in upper-level } \\
\text { courses }\end{array}$ & $\begin{array}{l}\text { Students exposes since freshman year to } \\
\text { hands-on concrete engineering design }\end{array}$ \\
\hline $\begin{array}{l}\text { High-level tools and simulators that hide the } \\
\text { details and appreciation of how devices } \\
\text { (routers, switches, firewalls, etc.) work }\end{array}$ & $\begin{array}{l}\text { Industrial tools used in the market-place that } \\
\text { provides both high level system design and } \\
\text { low level operational details }\end{array}$ \\
\hline
\end{tabular}

Consider the case of computer networks which is part of computer science, computer engineering, information (engineering) technology and other programs. Traditional programs offer an introductory course of computer networks as a 400-level course. Figure 2 shows the prerequisites for that course in a research institution in the NNMC state, for students enrolled in a computer engineering program. Such program may not be the most appealing for a curious student who enrolled to be an engineer to learn about computer networks. To be exposed to the 
subject, the student needs to first reach the senior year, to take 40+ credits and numerous math and other courses before being only introduced to the subject.

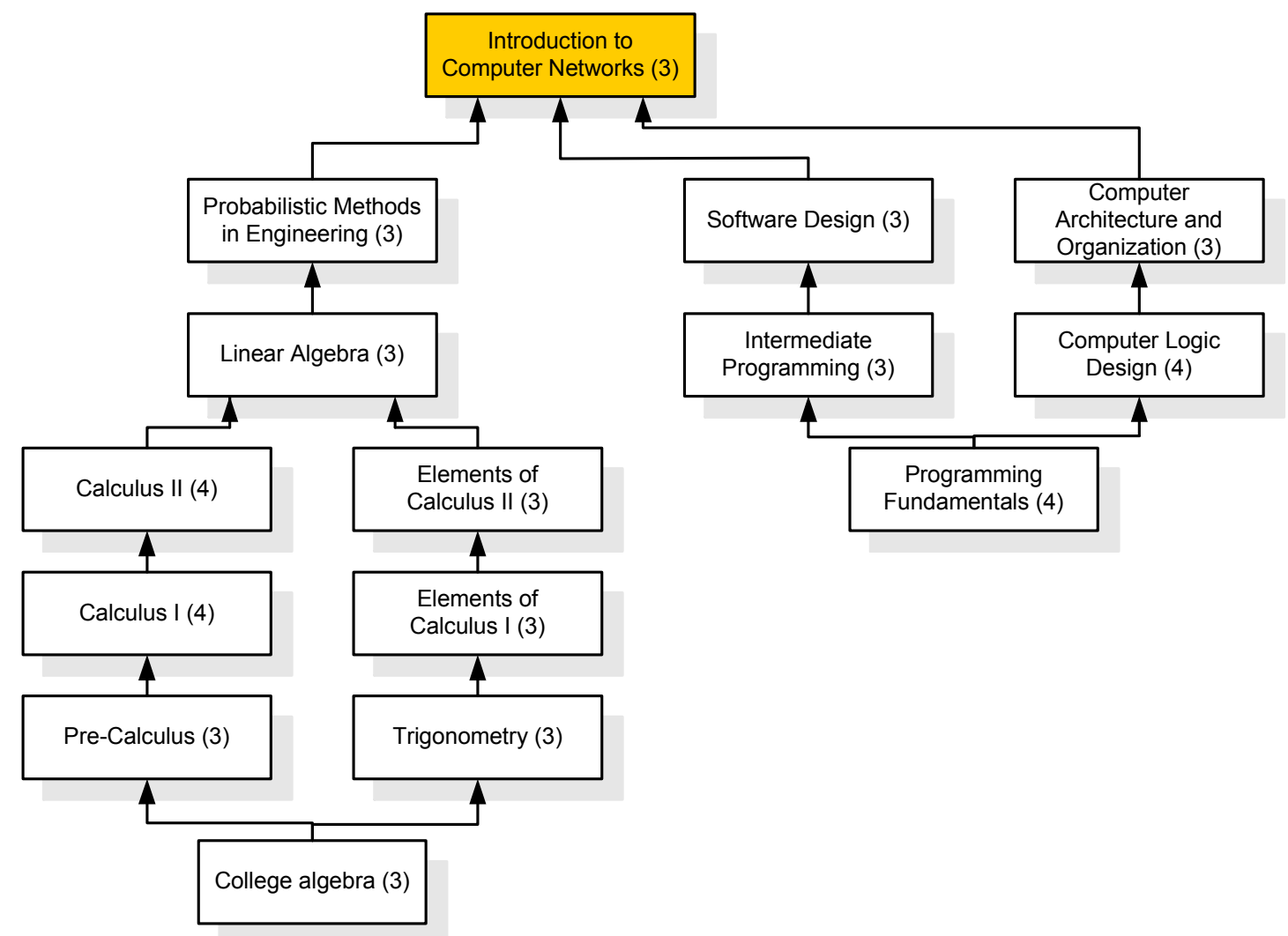

Figure 2. Typical pre-requisites for an introductory computer networks course. The numbers in parenthesis refer to credit hours.

In contrast, the learning-by-doing approach at NNMC has lower division courses that introduce students to the different pillars. These lower division courses are taken in parallel with math courses that are pre-requisites in traditional programs. By designing intensive hands-on courses, students are exposed to real equipment and appreciate the details of the engineering discipline. The math courses are therefore not removed from the program of studies. Moreover, the IET program strengthen the different pillars by offering students advanced level courses. For computer networks, three additional courses based on routing, wireless and switched networks, and advanced computer networks are available, as shown in Figure 3. 


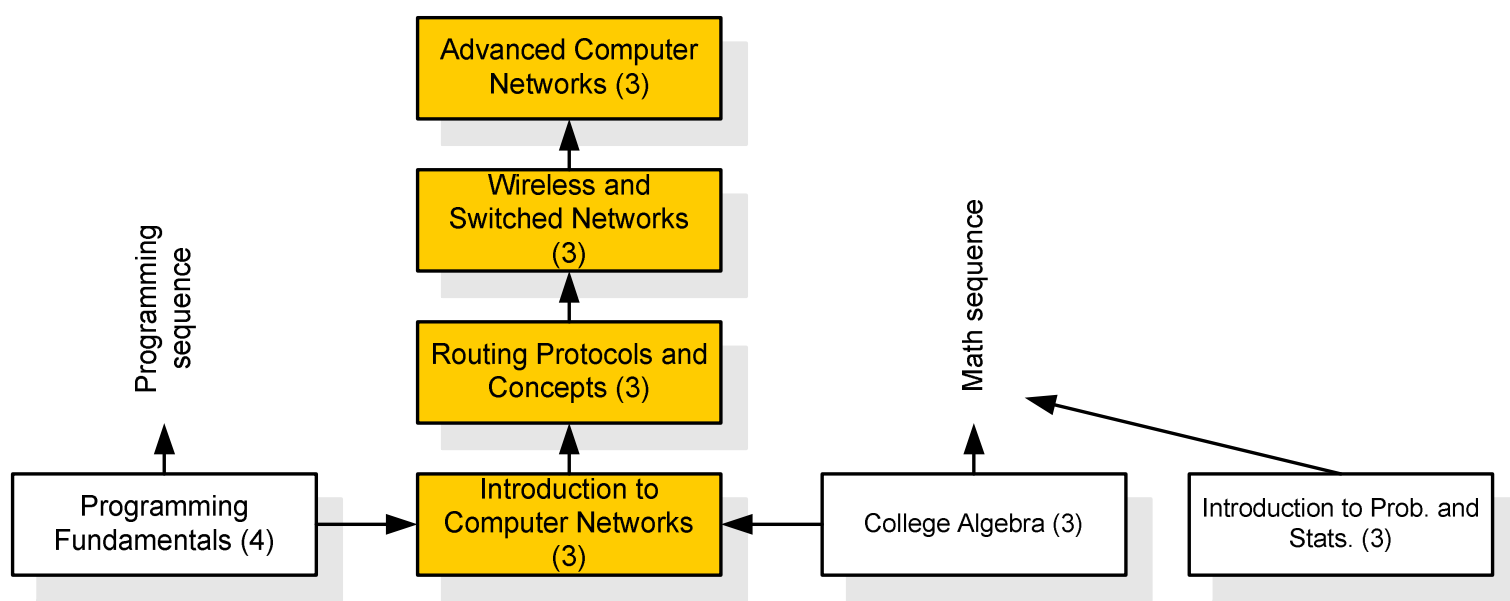

Figure 3. Articulation of computer networks courses in the IET program.

\subsection{Engineering content in the IET program}

Figure 4 provides an overview of the IET program. The number of credits required for graduation is 129 . While the program is a technology program, students are required to take core math and science courses (Calculus and Physics) as required by any engineering program. Specifically, students have to complete the math sequence up to Calculus II and Engineering Physics I and II (calculus-based). The IET program includes other engineering-based courses such as Discrete Mathematics and Algorithms, Circuit Analysis, and Computer Logic Design, thus providing students with engineering foundations. Senior students are required to take a yearlong senior design course (offered as two one-semester Capstone courses). As any Information Engineering Program, there are five specific ABET student outcomes (see Appendix I, student outcomes 12-16) that are attained through the learning material in the courses labeled as engineering foundations in Figure 4 and reinforced in 400-level courses. To acquire the background required for courses such as Circuit Analysis and Computer Logic Design, the IET program includes the course ENGR 120 Introductory Math for Engineering (see Figure 4). This course is organized as suggested by the Wright State Model ${ }^{3}$. These courses are typical in Computer Engineering and Electrical Engineering programs. Moreover, for the past two years, they have been offered at NNMC as cross-listed courses with the ECE program at University of New Mexico. 


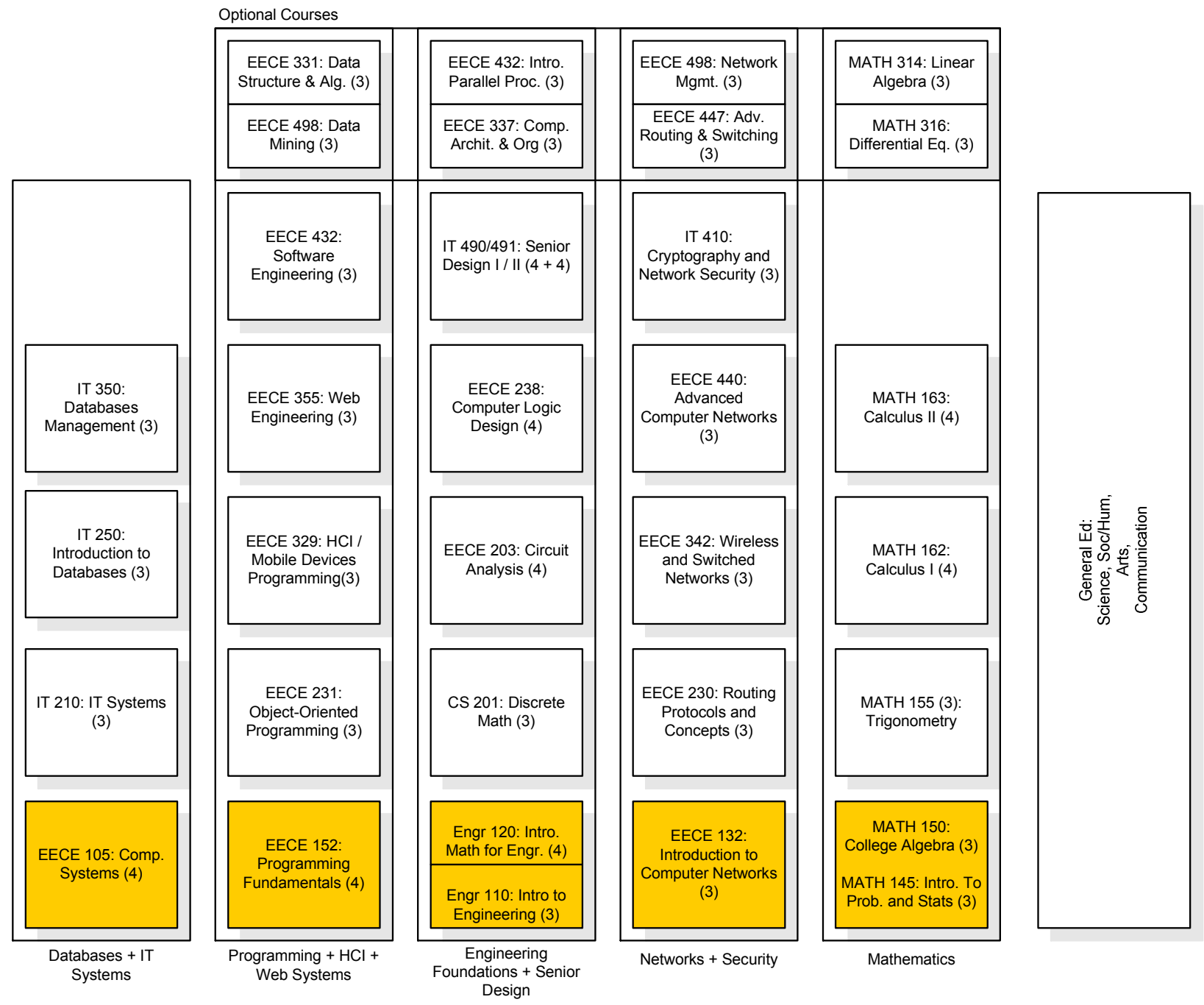

Figure 4. Overview of the IET program at NNMC. The five pillars of IT (Programming, Web Systems, HCI, Databases, and Computer Networks) are covered as suggested by ACM/IEEE ${ }^{5}$. Freshman courses are shown in yellow.

\subsection{Optional courses}

The program has a requirement of nine optional technical credits. Figure 4 shows some courses students may take to fulfill this requirement. Optional courses emphasize areas in computer science (Data Structures and Algorithms, Data Mining), computer networks (Advanced Routing and Switching, Network Management), math (Differential Equations, Linear Algebra), and engineering (Computer Architecture and Organization).

The optional courses are intended to allow for further breadth or depth according to the career path and area of interest. Those students who are interested in graduate school may be advised to take courses such as Differential Equations and Linear Algebra. Students interested in computer science may prefer to strengthen their knowledge with data structures, algorithms and math. 
Others who choose the industry path or IET field may prefer courses in networks, databases, or to prepare for industrial-type of certificates through advanced courses in security and networks (see industrial certificates section).

\subsection{Online content}

Multiple courses have substantial online content. For example, for the computer networks and security courses shown in Figure 4, students spend at least 150 minutes outside regular hours in activities such as quizzes and hands-on simulation-based labs. Table 2 shows the approximate weekly time requirements.

Table 2. Weekly activities for computer networks courses.

\begin{tabular}{|l|c|}
\hline \multicolumn{1}{|c|}{ Weekly activities } & Minutes \\
\hline Weekly lecture (in-class) & 75 \\
\hline Hands-on lab session (in-class) & 75 \\
\hline Hands-on simulation assignment lab (submission online) & 90 \\
\hline Online quiz (submission online) & 60 \\
\hline Overall & 300 minutes \\
\hline
\end{tabular}

Hands-on simulation lab assignments have to be completed before the in-class hands-on lab session. Simulation assignments (completed individually) and lab sessions (team work) are very similar; the former is completed using a network simulator, and the latter is completed with real equipment. Simulation assignments are pre-requisites for the in-class lab sessions. This arrangement provides greater interaction during lab session, because students already solved or attempted to solve the problem using a network simulator. The interaction created during lab hours also stimulates active learning.

\subsection{Industrial certificates}

The Department of Engineering at NNMC has established a partnership with Cisco Systems and created a local Cisco Network Academy. The advantages include the development of a curriculum that combines engineering theoretical foundations mixed with learning material appreciated by the industry, which permit to apply concepts to real-life problems. The IET program has an industrial advisory board that drives curricular changes according to the needs of the region. These needs are not different to those identified by the US Department of Labor; according to its estimation for the years 2012-2022, the computing and mathematical group of occupations will have 700,000 open positions ${ }^{6}$. The employment by specific occupation is also encouraging for IET areas such as computer networks and security professions, with increments in opening positions of $36.5 \%$ and $10-15 \%$ in security analysis and network-related specialists ${ }^{6}$. Over the past two years alone, the number of jobs requiring a Certified Information Systems Security Professional (CISSP) certification has jumped from 19,000 to more than $29,000^{7}$. 
IET students have the opportunity to be prepared for the Cisco Certified Network Associate (CCNA) certificates (routing, switching, and security). These certificate exams can be considered as de facto standard in networking qualification grading. Starting in Spring 2014, the course IT 410 Cryptography and Network Security includes all topics of the CCNA Security. CCNA Security is recognized by the National Security Agency (NSA) and the Committee on National Security Systems (CNSS) to meet the CNSS 4013 training standard. By being compliant with this standard, the certificate provides the required training for network security professionals who assist federal agencies and private sector entities to protect their information. For IET prospective graduates, this is a valued-added certificate since private companies and national labs (two of them in the proximity of NNMC) encourage employees to be certified. The Department is in the process of offering the Cisco Certified Network Professional (CCNP) by Fall 2014.

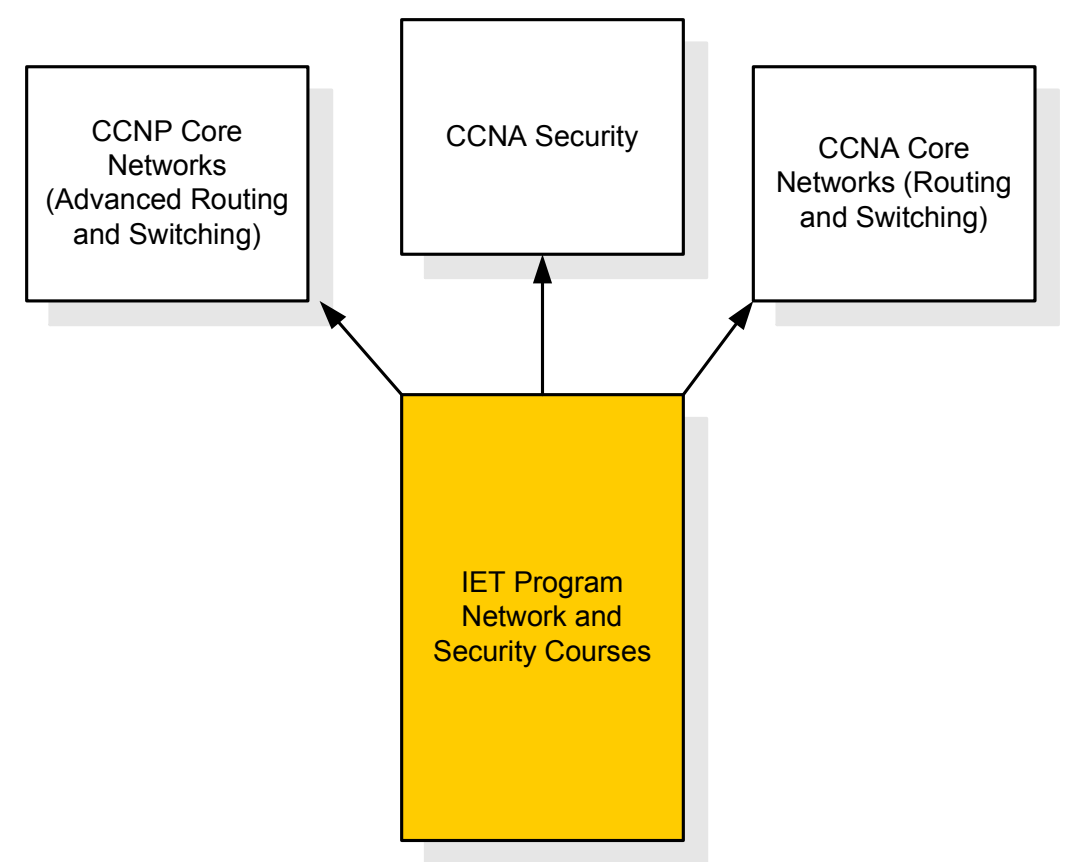

Figure 5. Certificates students may opt to obtain after taking the Network + Security courses (see Figure 4).

\section{Student outcomes: definition and assessment}

A fundamental building block of a program is the set of student outcomes. They describe what students are expected to know and be able to do by the time of graduation. These relate to the knowledge, skills, and behaviors that students acquire as they progress through the program ${ }^{8}$.

The process in the Department of Engineering for establishing and revising student outcomes relies upon the continual assessment of outcomes. In 2009, faculty members agreed to adopt 16 student outcomes composed of 11 standard outcomes of the general criterion 3 for Engineering Technology Programs for bachelor degrees (outcomes 1-11) published by the ABET ETAC 
commission for the 2009/2010 Accreditation Cycle; and five additional outcomes adopted from the published ABET ETAC commission Program Criteria for Information Engineering Technology for the 2009/2010 Accreditation Cycle (outcomes 12-16). Student outcomes are listed in Appendix I.

\subsection{Mapping of student outcomes to specific knowledge, techniques, and skills}

Each of the 16 student outcomes (SOs) is mapped to specific knowledge, techniques, and skills that are usually assessed and evaluated through hands-on activities identified by faculty members and aligned with input from the industrial advisory board. The following two are representative examples including computer networks courses of how student outcomes are associated with activities, knowledge, techniques, and skills. It is important to note that each of the 16 outcomes is assessed and evaluated in several courses.

Student Outcome 4. An ability to apply creativity in the design of systems, components, or processes appropriate to program educational objectives.

Table 3. Knowledge, technique, skills, and activities relevant to SO4.

\begin{tabular}{|l|l|l|}
\hline \multicolumn{1}{|c|}{ Code } & \multicolumn{1}{|c|}{ Name } & \multicolumn{1}{|c|}{ Activities, knowledge, techniques, and skills } \\
\hline EECE 132 & Computer Networks I & $\begin{array}{l}\text { Design, analyze, and test internetworks including } \\
\text { WANs and LANs, selecting appropriate routing such as } \\
\text { static routing (EECE 132) or advanced dynamic } \\
\text { routing protocols (EECE 330). }\end{array}$ \\
\hline EECE 330 & Computer Networks II \\
\hline EECE 330 & Computer Networks II & $\begin{array}{l}\text { Apply graph theory to route traffic according to } \\
\text { specifications. Design hierarchical networks and } \\
\text { manipulate OSPF link cost metric to achieve inter- and } \\
\text { intra-area communication. }\end{array}$ \\
\hline EECE 440 & $\begin{array}{l}\text { Advanced Comp. } \\
\text { Networks }\end{array}$ & $\begin{array}{l}\text { Apply linear programming to optimize performance of } \\
\text { MPLS networks. }\end{array}$ \\
\hline
\end{tabular}

Student Outcome 14. The ability to design, implement, maintain and provide for the security of facilities involved with the processing and transfer of information.

Table 4. Knowledge, technique, skills, and activities relevant to SO14.

\begin{tabular}{|c|l|l|}
\hline \multicolumn{1}{|c|}{ Code } & \multicolumn{1}{|c|}{ Name } & \multicolumn{1}{c|}{ Activities, knowledge, techniques, and skills } \\
\hline EECE 132 & $\begin{array}{l}\text { Computer } \\
\text { Networks I }\end{array}$ & $\begin{array}{l}\text { Secure routers (terminals and virtual terminals) using } \\
\text { password protection and encryption. }\end{array}$ \\
\hline EECE 342 & $\begin{array}{l}\text { Wireless and } \\
\text { Mobile } \\
\text { Computing }\end{array}$ & $\begin{array}{l}\text { Implement password protection mechanisms on switches for } \\
\text { virtual terminal connections. } \\
\text { Use WEP/WPA protocol to provide for security at access }\end{array}$ \\
\hline
\end{tabular}




\begin{tabular}{|c|c|c|}
\hline & & $\begin{array}{l}\text { points. } \\
\text { Apply port security and dynamic sticky MAC addresses at } \\
\text { the distribution segment of an } 801.11 \text { network (e.g., } \\
\text { Extended Service Set). } \\
\text { Implement switched networks using VLANs. }\end{array}$ \\
\hline IT 410 & $\begin{array}{l}\text { Cryptography } \\
\text { and Network } \\
\text { Security }\end{array}$ & $\begin{array}{l}\text { Use a PKI-based application to demonstrate how public-key } \\
\text { cryptography works. } \\
\text { Implement VPNs to authenticate remote sites and to send } \\
\text { data confidentially over an open network. }\end{array}$ \\
\hline EECE 440 & $\begin{array}{l}\text { Advanced } \\
\text { Computer } \\
\text { Networks }\end{array}$ & $\begin{array}{l}\text { Design and implement standard and extended network } \\
\text { access control lists using industrial firewalls. } \\
\text { Implement security mechanism such as Message Digest } 5 \\
\text { (MD5) to authenticate routing tables. }\end{array}$ \\
\hline
\end{tabular}

\subsection{Assessment and evaluation of student outcomes}

A fundamental activity for continuous improvement and accreditation is the assessment and evaluation of student outcomes. Thus, for each activity listed in Tables 3 and 4 used to measure the level of attainment of a student outcome, there must exist a target performance which is used to discriminate weather a student attain or not the student outcome. The Department of Engineering at NNMC defines the level of attainment of outcomes per student as follows:

- Target met: a student achieves $70 \%$ of the instrument scale (note that target refers now to an individual student performance).

- Target not met: a student does not achieve $70 \%$ of the instrument scale.

For the aggregate result for a student outcome measured in a class (including all students), the Department defines the level of attainment of outcomes per class as follows:

- Target met: $75 \%$ of all students or more achieve target.

- Target in progress: less than $75 \%$ of all students achieve target. Some assessment reports also identify "Target in progress" as "Target partially met."

In case that the target is in progress, faculty members devise action plans to be implemented to obtain the target.

Given that the level of attainment of a student outcome is measured in multiple classes, the Department defines the overall level of attainment of a student outcome for the Information Engineering Technology (IET) program as follows: 
- For 100-level and 200-level classes, the Department assigns 1 point if the level of attainment is marked as Target in progress.

- For 100-level and 200-level classes, the Department assigns 2 points if the level of attainment is marked as Target met.

- For 300-level and 400-level classes, the Department assigns 2 points if the level of attainment is marked as Target in progress.

- For 300-level and 400-level classes, the Department assigns 4 points if the level of attainment is marked as Target met.

The level of attainment of a student outcome considering all courses where the student outcome is measured, is defined as:

$$
\text { Level of attainment of outcome }=\frac{\text { Points achieved }}{\text { Maximum points in outcome }}
$$

It is important to carefully design the curriculum map so that each student outcome is assessed and evaluated in at least one upper-division course. Most IET student outcomes are assessed and evaluated in multiple upper-division and lower-division courses.

Tables 5 and 6 summarize the level of attainment of student outcomes corresponding to Tables 3 and 4. Each entry in each table is documented and attached to student work samples.

Student Outcome 4. An ability to apply creativity in the design of systems, components, or processes appropriate to program educational objectives.

Table 5. Level of attainment of student outcome 4.

\begin{tabular}{|c|l|l|c|c|c|c|}
\hline \multirow{2}{*}{ Code } & \multirow{2}{*}{ Name } & \multicolumn{5}{c|}{ Assessment Tool/Activity } \\
\cline { 3 - 7 } & & Exam & Quiz & $\begin{array}{c}\text { Hands-on } \\
\text { Lab }\end{array}$ & $\begin{array}{c}\text { Simulation } \\
\text { Lab }\end{array}$ & Project \\
\hline EECE 132 & $\begin{array}{l}\text { Computer } \\
\text { Networks I }\end{array}$ & In progress (1) & & & & \\
\hline EECE 330 & $\begin{array}{l}\text { Computer } \\
\text { Networks II }\end{array}$ & In progress (2) & & Met (4) & Met (4) & \\
\hline EECE 440 & $\begin{array}{l}\text { Advanced } \\
\text { Computer } \\
\text { Networks }\end{array}$ & & & Met (4) & & \\
\hline
\end{tabular}

Level of attainment of Outcome $4=\frac{\text { Points achieved }}{\text { Maximum points in outcome }}=\frac{15}{18}=0.83$ 
Student Outcome 14. The ability to design, implement, maintain, and provide for the security of facilities involved with the processing and transfer of information.

Table 6. Level of attainment of student outcome 14.

\begin{tabular}{|c|c|c|c|c|c|c|}
\hline \multirow{2}{*}{ Code } & \multirow{2}{*}{ Name } & \multicolumn{5}{|c|}{ Assessment Tool/Activity } \\
\hline & & Exam & Quiz & $\begin{array}{c}\text { Hands-on } \\
\text { Lab }\end{array}$ & $\begin{array}{c}\text { Simulation } \\
\text { Lab }\end{array}$ & Homework \\
\hline EECE 132 & $\begin{array}{l}\text { Computer } \\
\text { Networks I }\end{array}$ & In progress $(1)$ & & & & \\
\hline EECE 342 & $\begin{array}{l}\text { Wireless and } \\
\text { Mobile Computing }\end{array}$ & & & & Met (4) & \\
\hline IT 410 & $\begin{array}{l}\text { Info. Assurance \& } \\
\text { Security }\end{array}$ & & & & Met (4) & \\
\hline EECE 440 & $\begin{array}{l}\text { Advanced } \\
\text { Computer } \\
\text { Networks }\end{array}$ & & & Met (4) & & $\begin{array}{l}\text { In progress } \\
\text { (2) }\end{array}$ \\
\hline Level of & nment of $\mathrm{O}$ & me $14=$ & & ints achi & sed & $\frac{15}{18}=0.83$ \\
\hline
\end{tabular}

\subsection{Data collection}

The data collection process makes use of several direct assessment tools. Data collection in the previous tables includes:

- Exams: midterm or final exams.

- Quizzes: in-class or take-home assignments including mostly multiple-choice questions.

- Hands-on Labs: activities developed in laboratory; some are performed in groups.

- Simulation Labs: hands-on individual activities performed using a software simulator.

- Projects: course projects, e.g., the Capstone project.

- Homework: assignments that may include not only theoretical exercises but also handson exercises with software packages.

The IET program relies on hands-on activities to increase the level of attainment of student outcomes. Thus, as illustrated in Tables 5-6, the level of attainment of all students outcomes are measured with a combination of traditional homework assignments, exams and hands-on activities (simulation labs or hands-on labs).

Tables 5 and 6 illustrate an important aspect of the teaching methodology at NNMC. Students were always able to attain the target level of student outcomes 4 and 14 through hands-on labs and simulation labs. This confirms previous literature results that suggest that students learn by 
doing. This learning-by-doing approach is absolutely essential in computer networking in particular and engineering in general. Complete insight into the subtleties or an appreciation of how the technologies operate in practice can only be achieved through first-hand experience. Hands-on experiences reinforce concepts by forcing students to apply them and to achieve concrete results.

Rubrics are used to quantify the performance of a student on hands-on activities, which are sometime included even in homework assignments and exams. Figures 6 and 7 show two different rubrics: the quality design rubric of Figure 6 is an example of a general rubric used to evaluate a report of a lab assignment. The hands-on exercise rubric of Figure 7 is a rubric designed for a specific exercise. To successfully complete a hands-on activity (and thus receive a good rubric score), students have to apply theoretical concepts to real problems.

\section{Quality Design Rubric}

Course:

Date:
Team Members: Evaluator:

\begin{tabular}{|c|c|c|c|c|c|}
\hline $\begin{array}{l}\text { Performance } \\
\text { Indicator }\end{array}$ & $\begin{array}{c}5 \\
\text { High Proficiency }\end{array}$ & $\begin{array}{c}4 \\
\text { Proficiency }\end{array}$ & $\begin{array}{c}2 \\
\text { Some Proficiency }\end{array}$ & $\begin{array}{c}0 \\
\text { No/Limited } \\
\text { Proficiency }\end{array}$ & Score \\
\hline $\begin{array}{l}\text { Defining the } \\
\text { Problem }\end{array}$ & $\begin{array}{l}\text { Student states the } \\
\text { problem clearly and } \\
\text { identifies underlying } \\
\text { issues. }\end{array}$ & $\begin{array}{l}\text { Student adequately } \\
\text { defines the problem. }\end{array}$ & $\begin{array}{l}\text { Student fails to define } \\
\text { the problem adequately. }\end{array}$ & $\begin{array}{l}\text { Student does } \\
\text { not identify the } \\
\text { problem. }\end{array}$ & \\
\hline $\begin{array}{l}\text { Developing a Plan } \\
\text { to Solve the } \\
\text { Problem }\end{array}$ & $\begin{array}{l}\text { Student develops a clear } \\
\text { and concise plan to } \\
\text { solve the problem, with } \\
\text { alternative strategies. }\end{array}$ & $\begin{array}{l}\text { Student develops an } \\
\text { adequate plan. }\end{array}$ & $\begin{array}{l}\text { Student develops a } \\
\text { marginal plan. }\end{array}$ & $\begin{array}{l}\text { Student does } \\
\text { not develop a } \\
\text { coherent plan } \\
\text { to solve the } \\
\text { problem. }\end{array}$ & \\
\hline Specifications & $\begin{array}{l}\text { Student follows the } \\
\text { specifications, and } \\
\text { includes additional } \\
\text { features. }\end{array}$ & $\begin{array}{l}\text { Student follows the } \\
\text { specifications. }\end{array}$ & $\begin{array}{l}\text { Student changes some } \\
\text { specifications. }\end{array}$ & $\begin{array}{l}\text { Student does } \\
\text { not follow the } \\
\text { specifications. }\end{array}$ & \\
\hline $\begin{array}{l}\text { Interpreting } \\
\text { Findings and } \\
\text { Solving the } \\
\text { Problem }\end{array}$ & $\begin{array}{l}\text { Student provides a } \\
\text { logical interpretation of } \\
\text { the simulation and } \\
\text { findings, and clearly } \\
\text { solves the problem. }\end{array}$ & $\begin{array}{l}\text { Student provides a } \\
\text { logical but incomplete } \\
\text { interpretation of the } \\
\text { simulations and } \\
\text { findings, but solves the } \\
\text { problem. }\end{array}$ & $\begin{array}{l}\text { Student does not provide } \\
\text { an interpretation of the } \\
\text { simulations and } \\
\text { findings, but solves the } \\
\text { problem. }\end{array}$ & $\begin{array}{l}\text { Student does } \\
\text { not interpret } \\
\text { the } \\
\text { findings/reach } \\
\text { a conclusion. }\end{array}$ & \\
\hline
\end{tabular}

Figure 6. Quality Design Rubric used to quantify student performance on lab assignments. 


\section{Final Exam \\ Hands-on Exercise Rubric}

Name.

Date.

Score.

\begin{tabular}{|c|c|c|c|c|}
\hline Performance Indicator & 10 & 5 & 0 & Score \\
\hline $\begin{array}{l}\text { Implement VLANs in a switched } \\
\text { network }\end{array}$ & $\begin{array}{l}\text { Appropriate VLANs } \\
\text { implementation, including port } \\
\text { assignments and roles, IPs } \\
\text { assignments, VTP and STP }\end{array}$ & $\begin{array}{l}\text { VLANs are implemented but } \\
\text { design can be improved; e.g., } \\
\text { trunking optimization, port } \\
\text { roles }\end{array}$ & $\begin{array}{l}\text { No VLANs were } \\
\text { implemented }\end{array}$ & \\
\hline $\begin{array}{l}\text { Design routing scheme in } \\
\text { switched networks }\end{array}$ & $\begin{array}{l}\text { Optimal inter-VLAN routing } \\
\text { scheme is implemented, } \\
\text { according to the given scenario }\end{array}$ & $\begin{array}{l}\text { Inter-VLAN routing works but } \\
\text { is not optimal }\end{array}$ & $\begin{array}{l}\text { No inter-VLAN routing } \\
\text { implementation }\end{array}$ & \\
\hline
\end{tabular}

Figure 7. A rubric specifically designed to quantify student performance on a hands-on exercise.

\section{Impact of the IET model on students from their perspective}

The IET program has its first five graduates in Spring 2013. Besides the assessment and evaluation methodology presented in Section 4, the Department of Engineering has run several surveys and focused group interviews to capture the opinion of students about the IET program. This section presents the results of a computer networks survey that was administered to recent graduates and current students who have already taken one or more computer networks courses.

The survey was administered during the Fall 2013 and completed by the five recent graduates and 36 current students, for a total of 41; 90\% of respondents took EECE 132 Introduction to Computer Networks, approximately 60\% took also EECE 330 Routing Protocols and EECE 342 Wireless and Switched Networks, and $21 \%$ took the four computer networks courses (Figure 8).

With respect to the time allocated to each course, EECE 342 Wireless and Switched Networks may require more allocated time according to respondents (Figure 9); approximately $70 \%$ of those students who took such a class considered that 150 minutes per week suffices. It's believed that the content of VLANs and wireless networks may require more time for students to grasp concepts. Additionally, wireless lab sessions are generally more time consuming than other lab experiments such as routing and wide area networks. Another interesting observation is the fact that almost all students who took EECE 132 Introduction to Computer Networks felt comfortable with 150 minutes per week, very intensive (11 lab assignments, 11 online quizzes, and approximately 10 homework assignments including hands-on simulations) freshman class.

The responses regarding the level of difficulty is shown in Figure 10. Approximately 50\% of students who took EECE 342 consider this class the most difficult computer networks class. As discussed above, topics such as VLANs and wireless concepts appear to be more demanding for students because they require a higher level of abstraction. Labs covering VLANs and wireless have been identified as the most time consuming because they require substantial 
troubleshooting for proper operation. EECE 440, the most advanced level class, on the other hand, is considered to be less demanding. The reason of this is because students taking this class are usually senior and have a stronger background.

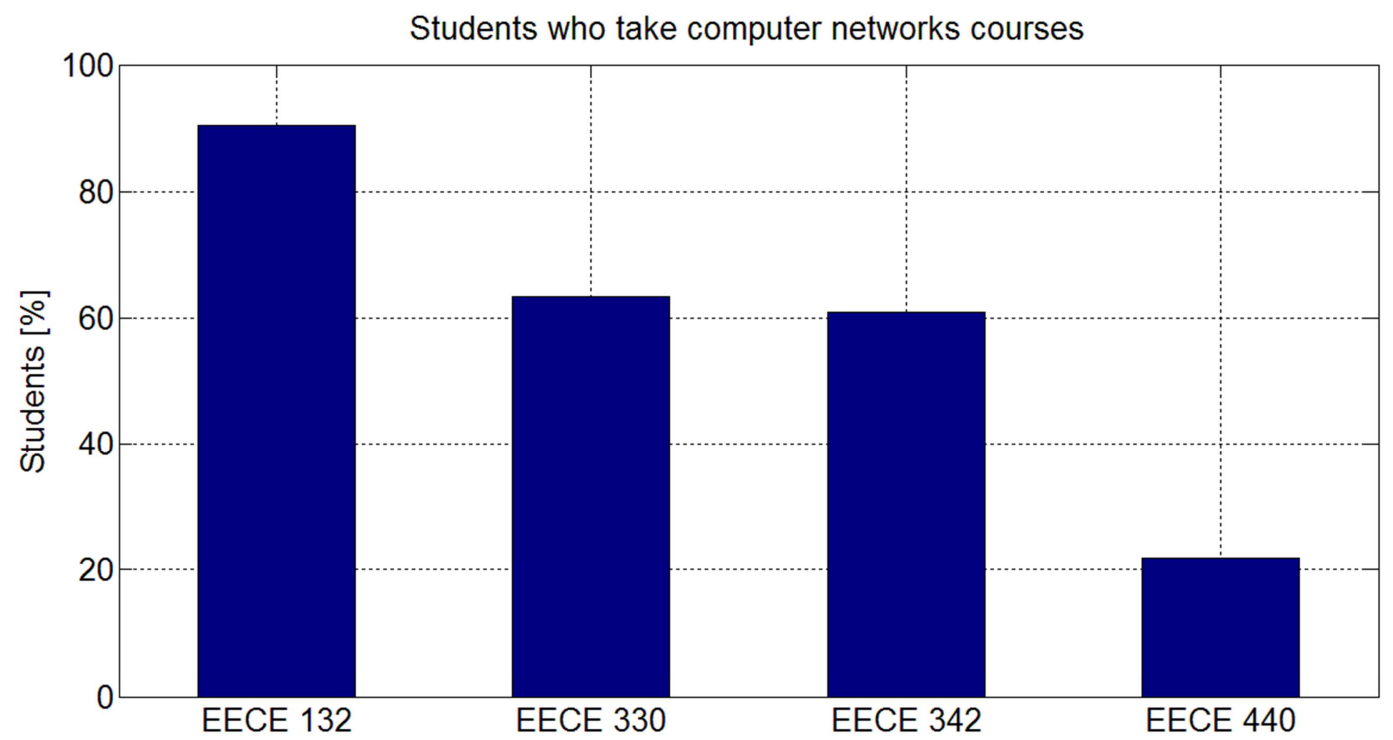

Figure 8. Participation of students in the computer networks survey. Out of 41 respondents, $90 \%, 61 \%, 60 \%$, and 21\% took EECE 132, EECE 330, EECE 342 and EECE 440.

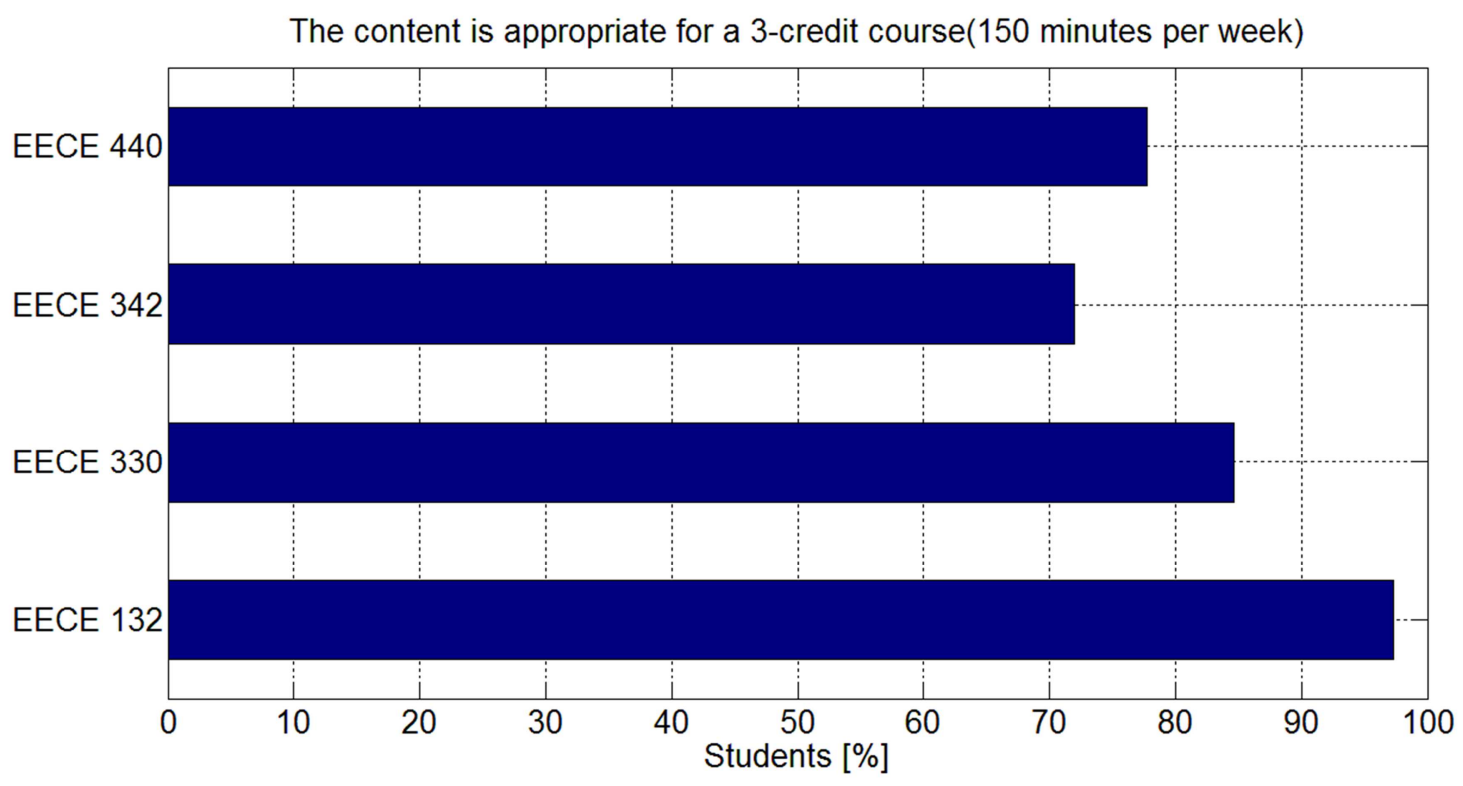

Figure 9. Responses of time allocation to computer networks courses. 


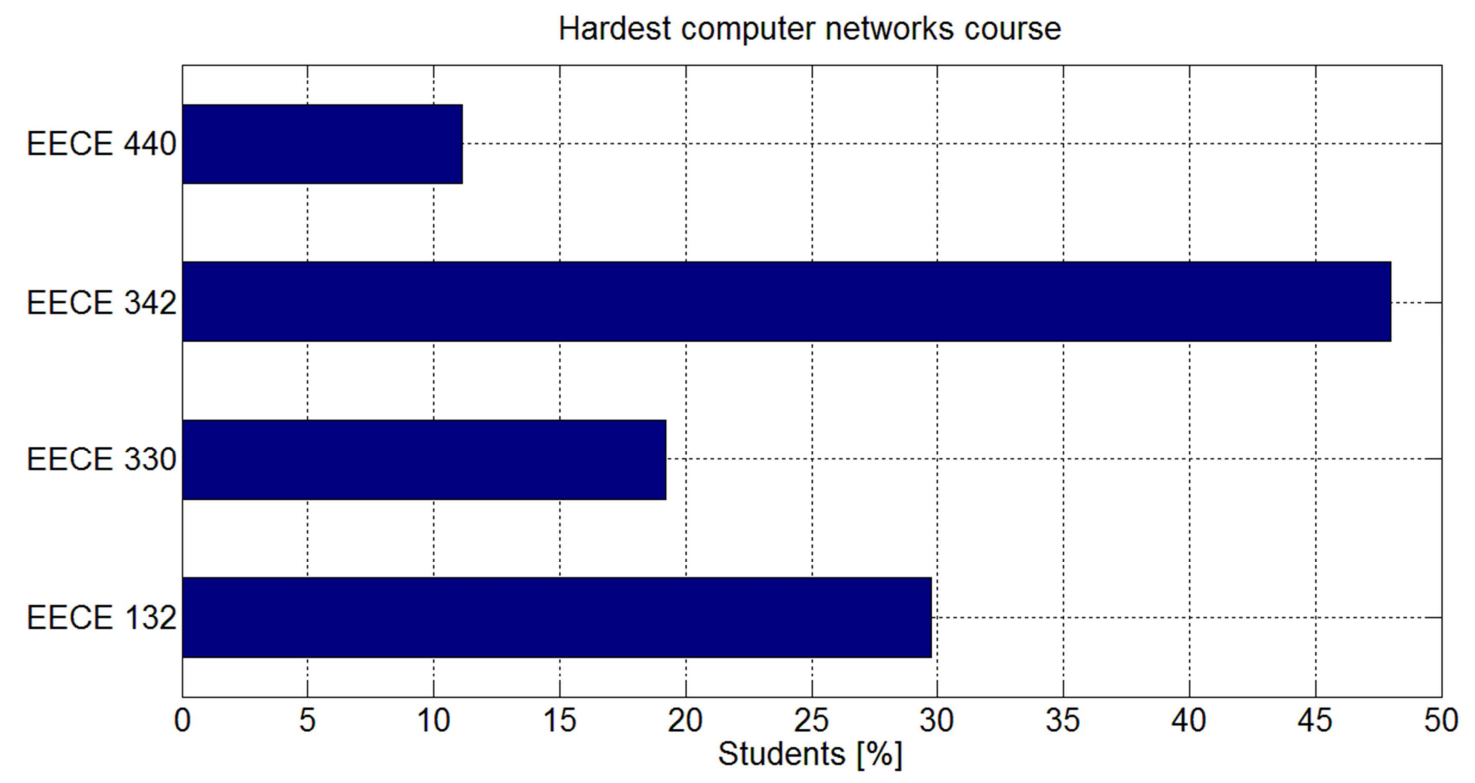

Figure 10. Responses regarding the level of difficulty. Almost 50\% of students who took EECE 342 believe that this class is the most difficult computer network class.

According to the survey, the pre-requisites are adequate for most of the students. The course the students feel less comfortable with their background knowledge is EECE 342, which is aligned with the previous observations.

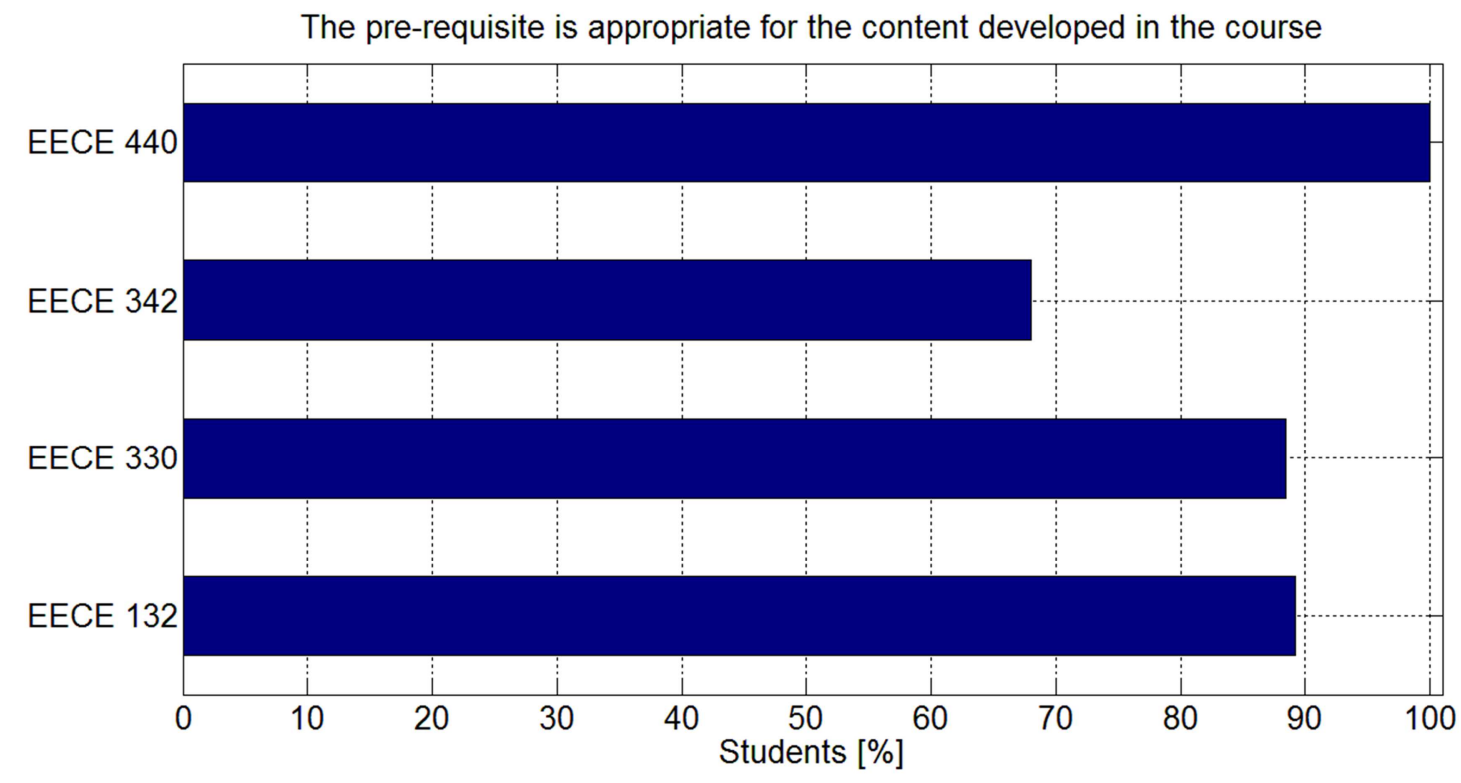

Figure 11. Responses regarding pre-requisites. All students who took EECE 440 believe the prerequisites of the course are adequate.

Figure 12 shows that more than $50 \%$ of the students apply concepts learned in class on their current job, internship, or any work-related experience. Most students at NNMC work part-time or have some type of internship experience (e.g., summer internships). This demonstrates that the 
content of the courses, which contain a mix of traditional-based theory and industrial-type of hands-on experiences, prepare them for the market-place. Additionally, while the equipment used in lab sessions are Cisco-based, the concepts learned in class are general. Moreover, most network equipment from different vendors operate in a similar way. Almost $30 \%$ responded that they operate wireless devices similar to those used in the lab; this observation confirms that professionals with knowledge on this area are in high demand.

Figure 13 depicts the responses to the question of areas of interest. More than $80 \%$ of respondents show interest in the area of computer networks to pursue a career in. An unexpected result is the high interest in the security area. In consultation with the industrial advisory board and as a result of the market demand, the IET program includes now (starting in Spring 2014) an intensive hands-on course in cryptography and network security (IT 410, see Figure 4). It is important to highlight that this course requires a background on discrete math (CS 201), and computer networks (EECE 330 and EE 342). Students will be able to opt for the CCNA Security certificate once they pass the course IT 410.

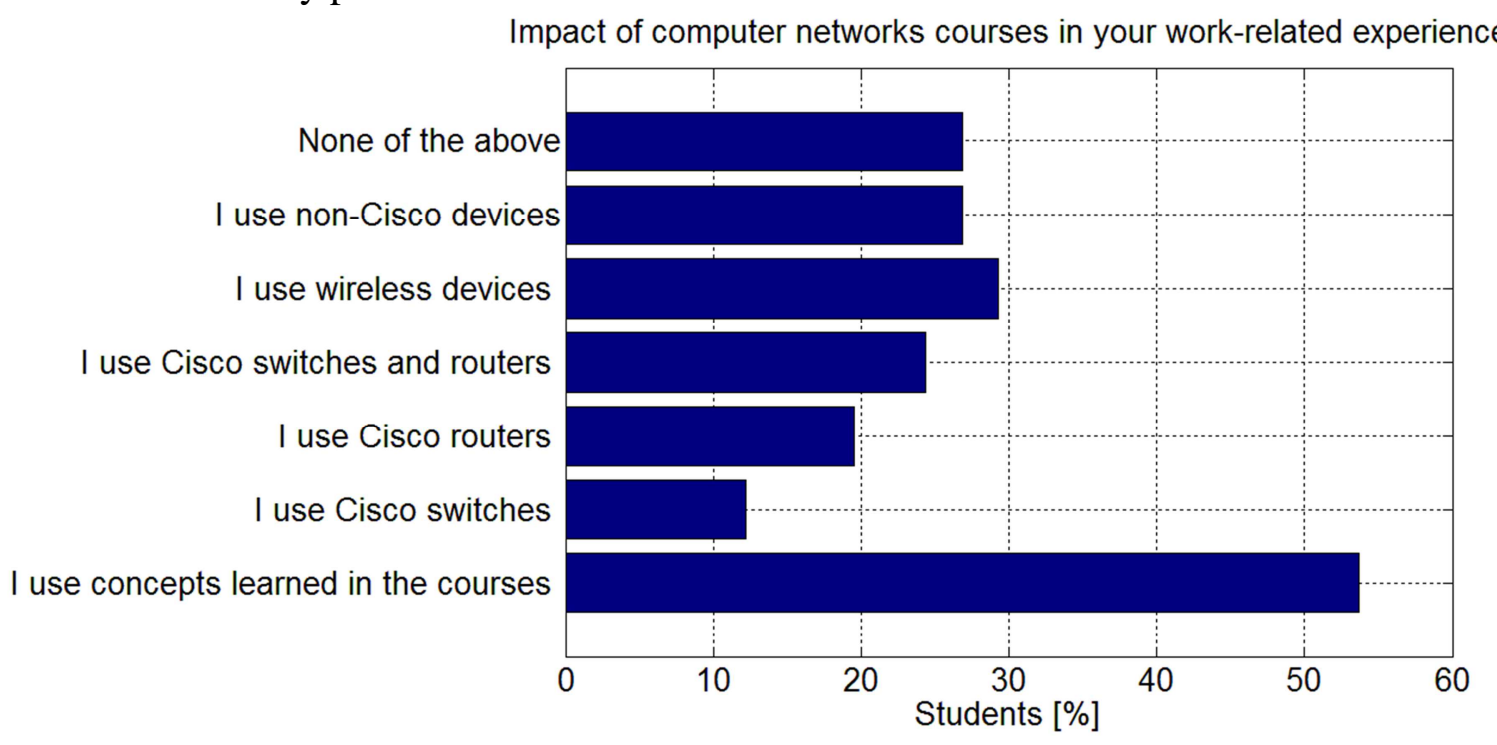

Figure 12. Impact of knowledge acquired in computer networks course on work-related experiences. 


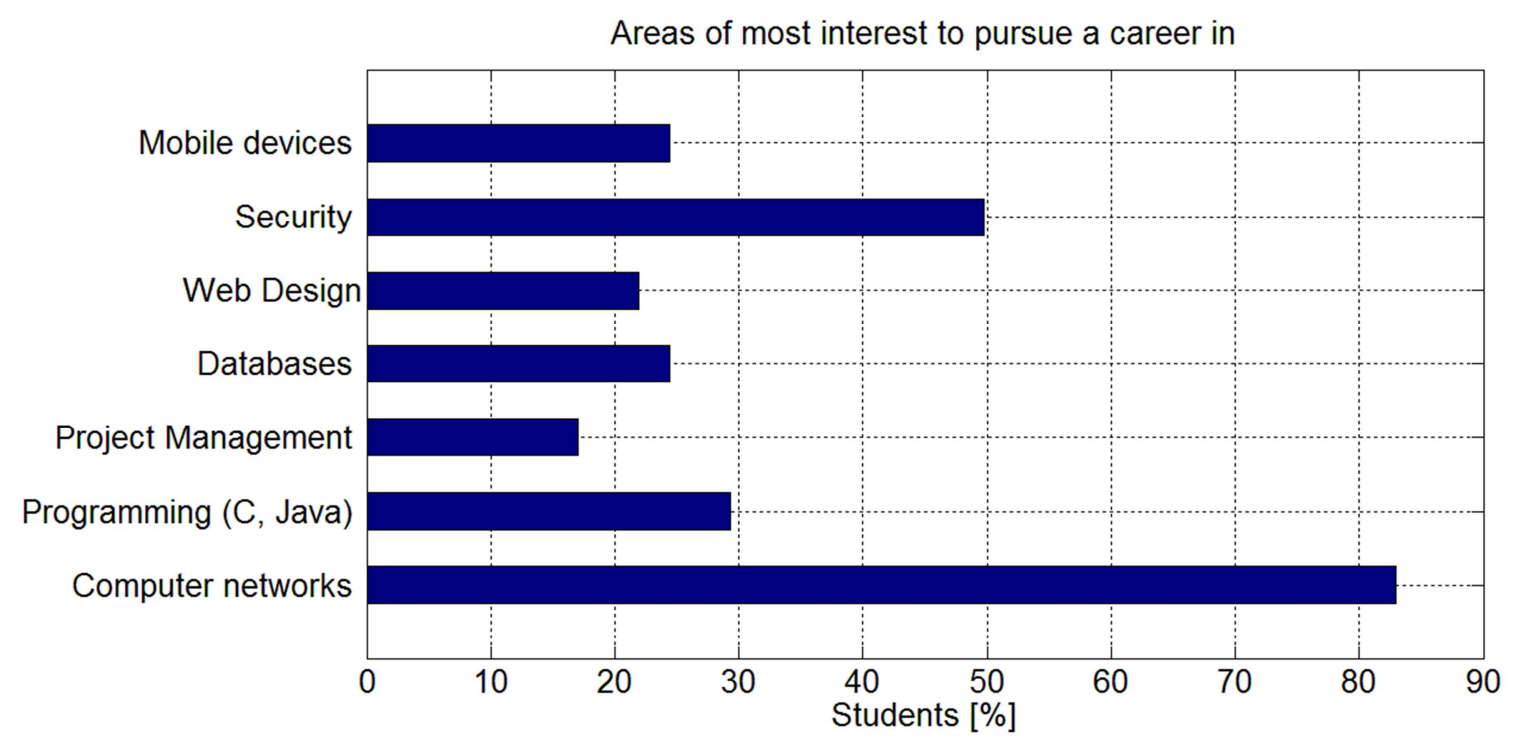

Figure 13. Interest of students in different areas covered by the IET program.

Figure 14 shows the salary distribution based on those respondents who provided their income (21 out of 41). In analyzing the results, it is important to remember that i) NNMC is located in a high-poverty area where a medium household income is approximately $\$ 35,000$, and ii) more than $90 \%$ of respondents are current students of the IET program (only 10\% are graduates). A first observation is that $28 \%$ has a salary between $\$ 35,000-39,000$, indicating that those (presumably) students who work part time and go to school for an IET degree already are in the same category as the medium household income of the city. A second observation is that $36 \%$ of respondents have an income of $\$ 60,000$ or more. Among those respondents are (presumably) the five graduates of the IET program. Note also that $60 \%$ of respondents are in the bracket of $\$$ 50,000 or more. All the students live in the region; even the graduates who may have opted to move out of the region and to earn higher salaries decided to stay. The income level of Figure 14 represents either entry-level salaries (for recent graduates) or part-time salaries (current students). 


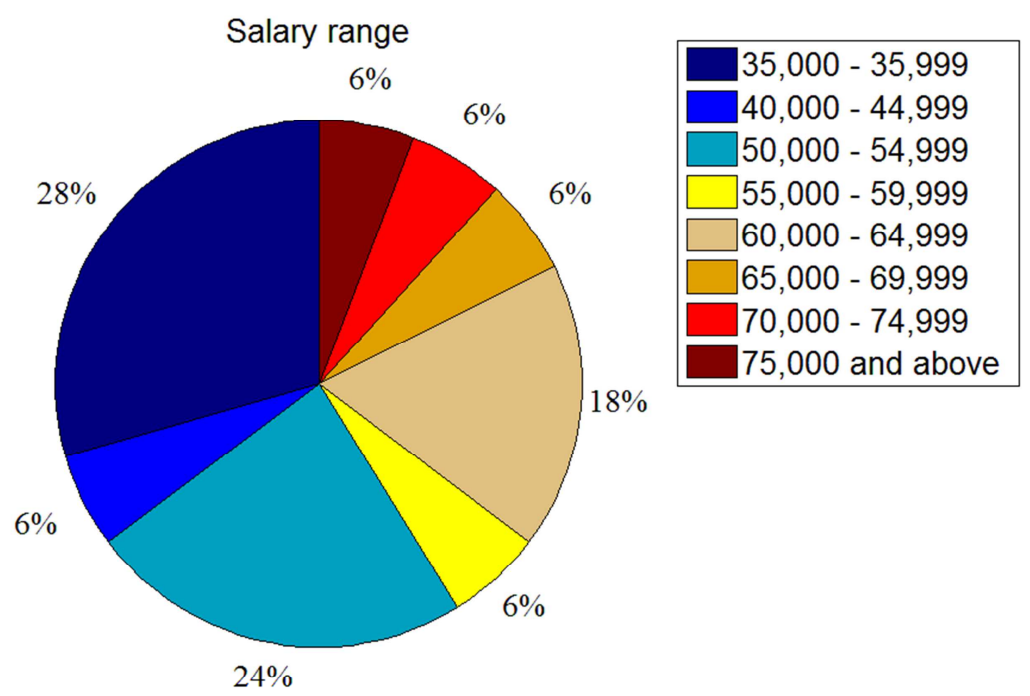

Figure 14. Out of 41 participants, 21 respondents provided their salary. The chart is based on those participants.

\section{Conclusion}

This paper presented the implementation of an Information Engineering Technology program that borrows from traditional engineering programs to build student foundations and at the same time prepares industry-ready professionals. The paper described the building blocks of the program, focusing on curriculum and student outcomes. The IET curriculum is based on a learning-by-doing approach and includes intensive hands-on activities. By partnering with the industry, students are exposed since their freshman year to real industrial tools, hands-on activities and simple engineering design. Assessment and evaluation of student outcomes, collected through direct and indirect measures, demonstrate the effectiveness of the IET program to prepare students for the market-place and for attaining student outcomes. 


\section{References}

1. Engineering vs Engineering Technology. ABET website: http://www.abet.org/engineering-vsengineering-technology

2. T. Grose, The Missing Element, Prism Magazine, September 2013.

3. N. Klingbeil, K. Rattan, M. Raymer, D. Reynolds, R. Mercer, The Wright State Model for Engineering Mathematics Education: A Nationwide Adoption, Assessment and Evaluation, ASEE Annual Conference \& Exposition, Austin, TX, June, 2009.

4. J. Crichigno, I. Lopez, An Alternative Model for Computer Networks Education in Computing Disciplines, ASEE Annual Conference and Exposition, San Antonio, TX, June 2012.

5. Curriculum Guidelines for Undergraduate Degree Programs in Information Technology, Association for Computing Machinery (ACM) and IEEE Computer Society, 2008.

6. United States Department of Labor, Bureau of Labor Statistics. Information available online at: http://www.bls.gov/emp/ep_table_102.htm.

7. J. Vijayan, Demand for IT Security Experts Outstrips Supply, ComputerWorld Magazine, March 2013.

8. ABET, Assessment Planning. Information available online at: http://www.abet.org/assessment-planning/. 


\section{Appendix I. IET Student Outcomes}

The student outcomes of the IET program are composed of 11 standard outcomes of the general criterion 3 for Engineering Technology Programs for bachelor degrees (outcomes 1-11) published by the ABET ETAC commission for the 2009/2010 Accreditation Cycle; and five additional outcomes adopted from the published ABET ETAC commission Program Criteria for Information Engineering Technology for the 2009/2010 Accreditation Cycle (outcomes 12-16).

1. An appropriate mastery of the knowledge, techniques, skills, and modern tools of their disciplines.

2. An ability to apply current knowledge and adapt to emerging applications of mathematics, science, engineering, and technology.

3. An ability to conduct, analyze and interpret experiments, and apply experimental results to improve processes.

4. An ability to apply creativity in the design of systems, components, or processes appropriate to program educational objectives.

5. An ability to function effectively on teams.

6. An ability to identify, analyze and solve technical problems.

7. An ability to communicate effectively.

8. A recognition of the need for, and an ability to engage in lifelong learning.

9. An ability to understand professional, ethical and social responsibilities.

10. A respect for diversity and a knowledge of contemporary professional, societal and global issues.

11. A commitment to quality, timeliness, and continuous improvement.

12. The application of Computer and network hardware, operating systems, system and network administration, programming languages, applications software, and databases in the building, testing, operation, and maintenance of hardware and software systems.

13. The application of electrical, electronic, telecommunications, and digital signal propagation fundamentals in the building, testing, operation and maintenance of hardware and software systems.

14. The ability to design, implement, maintain and provide for the security of facilities involved with the processing and transfer of information.

15. The ability to apply project management techniques to facilities that process and transfer information.

16. The ability to apply discrete mathematics, and probability and statistics in the support of facilities that process and transfer information. 